\title{
Emerging insights into the genetic basis of canine hip dysplasia
}

This article was published in the following Dove Press journal:

Veterinary Medicine: Research and Reports

20 May 2015

Number of times this article has been viewed

\section{Mário Ginja' \\ Ana Rita Gaspar' \\ Catarina Ginja ${ }^{2,3}$}

'Department of Veterinary SciencesCITAB, University of Trás-os-Montes and Alto Douro, Vila Real, Portugal;

${ }^{2} \mathrm{Ce} 3 \mathrm{C}$ - Centro de Ecologia,

Evolução e Alterações Ambientais, Faculdade de Ciências, Universidade de Lisboa, Lisboa, Portugal; ${ }^{3} \mathrm{CIBIO}$ InBIO - Centro de Investigação em Biodiversidade e Recursos Genéticos, Universidade do Porto, Vairão, Portugal

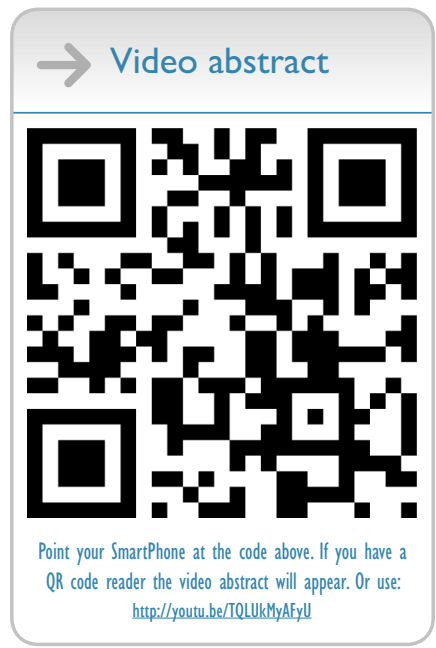

Correspondence: Mário Ginja Department of Veterinary ScienceCITAB, University of Trás-os-Montes and Alto Douro, Quinta de Prados, 5000-80 I Vila Real, Portugal

Tel +35 I 259350666

Fax +35I 259350480

Email mginja@utad.pt
Abstract: Canine hip dysplasia (CHD) is the most common inherited polygenic orthopedic trait in dogs with the phenotype influenced also by environmental factors. This trait was described in the dog in 1935 and leads to a debilitating secondary hip osteoarthritis. The diagnosis is confirmed radiographically by evaluating signs of degenerative joint disease, incongruence, and/or passive hip joint laxity. There is no ideal medical or surgical treatment so prevention based on controlled breeding is the optimal approach. The definitive CHD diagnosis based on radiographic examination involves the exposure to ionizing radiation under general anesthesia or heavy sedation but the image does not reveal the underlying genetic quality of the dog. Phenotypic expression of CHD is modified by environmental factors and dogs with a normal phenotype can be carriers of some mutations and transmit these genes to their offspring. Programs based on selection of dogs with better individual phenotypes for breeding are effective when strictly applied but remain inferior to the selection of dogs based on estimation of breeding values. Molecular studies for dissecting the genetic basis of CHD are ongoing, but progress has been slow. In the future, the recommended method to improve hip quality in controlled breeding schemes, which will allow higher selection pressure, would be based on the estimation of the genomic breeding value. Since 2012, a commercial DNA test has been available for Labrador Retrievers using a blood sample and provides a probability for development of CHD but we await evidence that this test reduces the incidence or severity of CHD.

Keywords: canine hip dysplasia, phenotype, breeding stock, GWAS, screening, diagnosis

\section{Introduction}

Canine hip dysplasia (CHD) is the most common inherited polygenic orthopedic trait with the phenotype influenced by environmental factors. ${ }^{1}$ This trait was described in the dog in 1935, in the USA, and leads to a debilitating secondary hip osteoarthritis. ${ }^{2}$ Heritability estimates for CHD vary from 0.1 to $0.83,{ }^{3,4}$ due to different pedigrees, methods used to calculate the heritability, and the hip phenotypes analyzed. ${ }^{5}$ CHD is more prevalent in large and giant breeds of dogs often resulting in mild or no clinical signs. ${ }^{1,6}$ However, for some dogs clinical signs can be severe and resistant to medical management needing aggressive and expensive surgical treatments. ${ }^{1,7}$ The definitive diagnosis of CHD is made if characteristic radiographic signs are evident on a standard or stressed ventrodorsal view of the pelvis, occurring along a gradual scale from nearly normal to severely affected. ${ }^{1}$ This is a crucial aspect of CHD as the radiographic diagnosis has been essential for the selection of breeding stock. ${ }^{1}$ Studies attempting to find genetic markers for CHD diagnosis are now frequent. ${ }^{8-11}$ The sequencing and annotation of the canine genome has resulted in renewed interest in research of the 
genetic underpinnings of canine orthopedic disorders, particularly those of a multifactorial etiology, such as CHD. ${ }^{12}$ Recently, the first commercial CHD diagnostic genetic test for Labrador Retrievers appeared, ${ }^{13}$ but, the imaging diagnosis continues to be of major importance for disease screening and treatment. Humans are also affected by hip dysplasia and both conditions have phenotypic similarities of joint subluxation and the development of osteoarthritis. ${ }^{14}$ However, the main medical approach in humans is different, being mainly based on the preventive management and with good results. ${ }^{1,15}$ Currently, molecular CHD studies are considered useful for the understanding of the genetic basis of analogous conditions in humans, mainly because the heterogeneity in human populations and the complexity of this disorder makes the genetic dissection of human hip osteoarthritis more difficult. ${ }^{12}$ The main purpose of this review is to present and discuss medical aspects of CHD for which knowledge is incomplete and have therefore merited major current research efforts.

\section{Epidemiology, physical signs, and outcomes}

CHD continues to be a common trait mainly in large and giant breeds, in pet and working dogs, with prevalence higher than $50 \%$ in some breeds. ${ }^{2}$ The clinical presentation of the disease is not correlated with the radiographic changes. ${ }^{2,6}$ Clinical signs of CHD are more evident in dogs younger than 1 year of age due to hip instability, or in adult dogs with chronic pain from osteoarthritis. ${ }^{7,16}$ Chronic hip alterations, such as fibrosis and thickening of the joint capsule, result in joint stability and improvement of limb function, masking the clinical signs and functional limitations in middle-aged animals. ${ }^{6,17}$ Clinical signs warrant medical and/or surgical treatment. ${ }^{18,19}$ Preventive conservative or surgical management could be indicated in puppies at risk of developing CHD, ${ }^{19,20}$ but early intervention is hampered because there are no pathognomonic clinical signs for CHD. Common clinical signs are: slight to moderate lameness; gait and running abnormalities, such as shortened stride length and bunny hopping; difficulty in rising and reluctance to climb stairs. ${ }^{21}$

\section{Diagnosis - physical examination and imaging}

Information about the conformation of the hip joint can be obtained using clinical or diagnostic imaging tests. ${ }^{21,22}$ These medical tests are usually performed on sedated or anesthetized animals and are separated into two main categories: to evaluate hip joint laxity (HJL), mainly used on young animals; to detect clinical or radiographic signs of osteoarthritis, as crepitation and reduced range of motion on joint palpation or degenerative joint disease (DJD) signs on radiographs. ${ }^{1,21}$ However, it would be very helpful to develop medical CHD screening techniques for fully conscious young animals, similar to hip dysplasia screening examination of human neonates. ${ }^{1}$ The imaging diagnosis of $\mathrm{CHD}$ has been the main area of research of CHD in the last 50 years, for the purposes of reproductive control. Clearly, in terms of human medicine the main focus has been different, trying to refine diagnostic accuracy and preventive management. ${ }^{1,15}$

\section{Physical examination}

The Ortolani test is the most common and popular physical maneuver that is used in veterinary medicine to diagnose HJL in young dogs (4-12 months of age). ${ }^{23,24}$ Other clinical tests are described, like the Barlow's and Barden tests for puppies younger than 4 months of age but their clinical accuracy is more questionable. ${ }^{1,17}$ The Ortolani test is performed with the dog awake, sedated or anesthetized with the patient in lateral or dorsal recumbency. ${ }^{23}$ The test has two steps, first apply proximal force to the stifle joint on the non-dependent limb, with the hip at a normal weight-bearing angle, and while still applying this force, slowly abduct the joint. In hips with abnormal laxity, the dysplastic femoral head, may be displaced dorsally beyond the dorsal acetabular rim (in the first step) and then the limb abduction promotes its reduction back into the acetabulum (in the second step) which elicits a typical palpable and/or audible clunk, of variable magnitude, commonly called a positive Ortolani sign (Figure 1). 1,23 Advanced stages of CHD with destruction of the acetabular rim or in dogs younger than 4 months of age with an inadequate acetabular ossification can result in false negative cases based on the Ortolani maneuver even though HJL may be present. ${ }^{17,24,25}$ The Ortolani test showed an excellent sensitivity in prediction of CHD when used in dogs younger than 1 year of age that later developed moderate or severe $\mathrm{CHD}^{24}$

\section{Diagnostic imaging}

Radiography is the reference technique for the definitive diagnosis of CHD from its first description in 1935. This imaging technique uses different radiographic views of the hip joint for genetic screening purposes or for diagnosis and treatment of dogs with clinical CHD. All these radiographic techniques should be performed under anesthesia or heavy sedation, which facilitates accurate positioning and elicitation of passive HJL. 1,3,7,19 Given the complexity of the topic and the objectives of this review, we will cover particularly the 

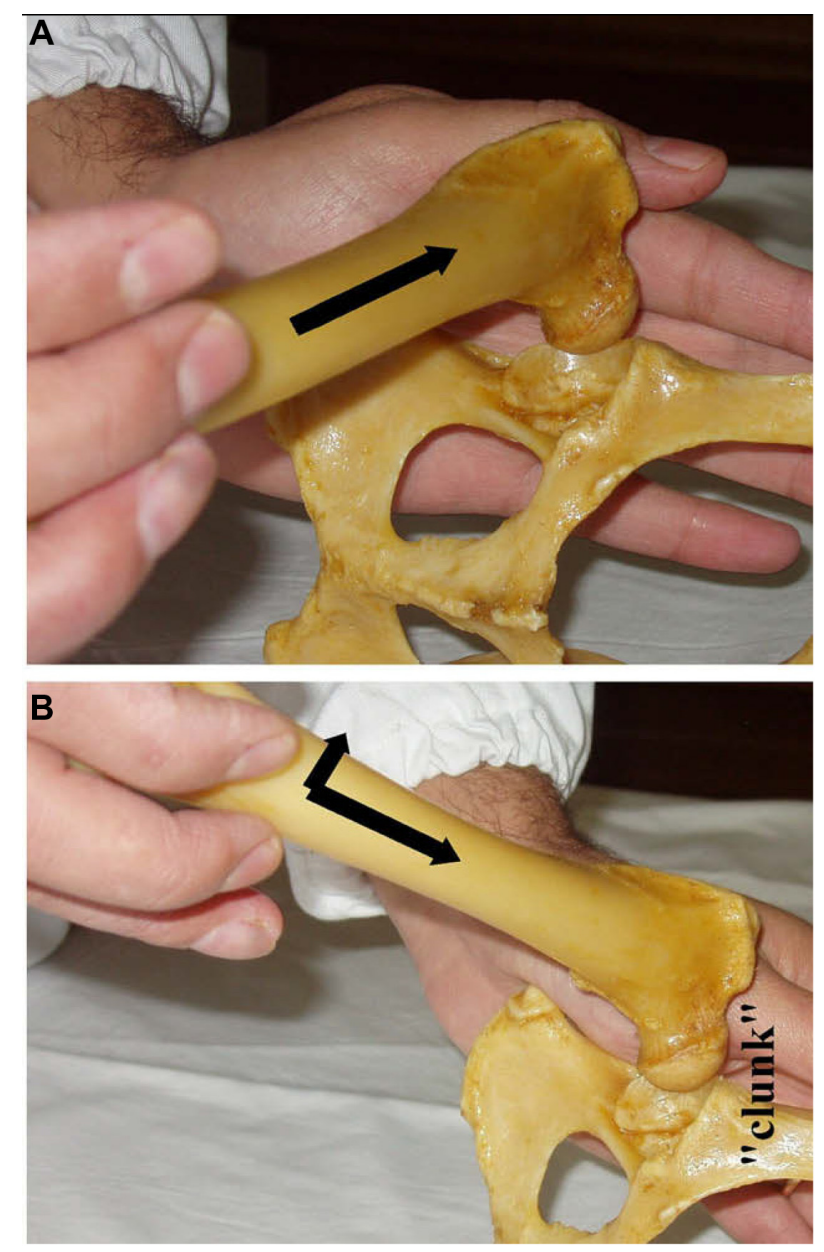

Figure I Ortolani test performed with the dog in lateral recumbency.

Notes: The hip is positioned in a neutral position with the femur parallel to the table and firm pressure is applied along the long axis of the femur (arrow), which causes subluxation of the femoral head when there is increased hip joint laxity (A). While still applying proximal force, the limb is slowly abducted (arrow), and the femoral head brought back into position within the acetabulum eliciting a typical palpable and/or audible clunk (B).

Reprinted from The Veterinary Journal, 184(3), Ginja MM, Silvestre AM, GonzaloOrden JM, Ferreira AJ. Diagnosis, genetic control and preventive management of canine hip dysplasia: a review, 269-276. Copyright (2010), with permission from Elsevier.'

radiographic studies used for genetic screening of CHD, which are used to detect HJL, the major risk factor for CHD, or signs of DJD.

The radiographic information on HJL is obtained using radiographic techniques such as PennHIP, ${ }^{26}$ dorsolateral subluxation (DLS), ${ }^{27}$ Flückiger ${ }^{28}$ and half-axial position methods. ${ }^{22}$ Signs of DJD are evaluated using the standard ventrodorsal hip-extended view (SVDV). 2,29,30

\section{Radiographic estimation of $\mathrm{HJL}$}

In this group of methods, the PennHIP was the pioneer and is the most popular. It was developed at the University of Pennsylvania in the 1980s with the main purpose of CHD breeding control. ${ }^{26}$ One of the main advantages of this procedure is its precocity, being performed with accuracy on dogs at 16 weeks of age, compared with 1 or 2 years of age for previous screening systems. ${ }^{26,29,30}$ The PennHIP method requires certified members and is performed with three hip radiographic views: hip-extended, compression, and distraction. ${ }^{26}$ The distraction view is used to measure HJL. It is performed with the dog in dorsal recumbency, with the hips at a neutral position and the PennHIP distractor between hind limbs acting as a fulcrum lateralizing the femoral heads under examiner force. ${ }^{26}$ The radiographs are sent to the PennHIP Analysis Center at University of Pennsylvania for an official report, and the dogs are placed in rank-order with the other dogs of the breed in the database. The HJL is evaluated in the distraction view calculating the distraction index (DI), which measures the relative degree of femoral head displacement from the acetabulum., ${ }^{3,26}$ The DI ranges from 0 to $>1$, with 0 representing a tight hip and 1 a loose hip. ${ }^{26}$

The DLS is also a passive stress radiographic or tomographic imaging technique; the HJL is measured as the DLS score ${ }^{27}$ The hip stress is caused by weight bearing. The DLS score has a strong correlation with DI. This method was reported in dogs at 4 and 8 months of age to evaluate the chondro-osseous acetabular and femoral head structure as an indicator of functional joint stability. ${ }^{27,31}$

In the Flückiger method, the HJL is estimated with the subluxation index in a similar manner to the DI. ${ }^{28}$ The stress in hip joints is caused by the dorsocranial force exerted by the examiner, with the dog in dorsal recumbency ${ }^{28}$ No follow-up studies were published and the research was performed in adult animals together with the SVDV to better assess the quality of the hips.

The half-axial position method was used by positioning the dog and performing the hip stress similar to the PennHIP, using a trapezoidal-shaped distractor. ${ }^{22}$ The HJL measures using this method are performed mainly with the purpose of early CHD diagnosis and treatment, using the juvenile pubic symphysiodesis (JPS).

\section{Radiographic evaluation of DJD}

The DJD is evaluated using the SVDV, a universal radiographic view used in dogs older than 1 (Fédération Cynologique Internationale's [FCI] system) or 2 years (Orthopaedic Foundation for Animals [OFA] system) of age. ${ }^{1,29}$ This view has been used since the $1960 \mathrm{~s} .{ }^{32}$ The dog is placed in dorsal recumbency on the X-ray table, with hind limbs extended parallel to each other with the stifles internally rotated. ${ }^{1,32}$ Many international systems are used to 
evaluate DJD, including the FCI, ${ }^{1} \mathrm{OFA},{ }^{29}$ British Veterinary Association/Kennel Club (BVA/KC), ${ }^{30}$ and the Flückiger ${ }^{33}$ method with more influence in continental European countries, USA, UK and Australia, and Switzerland, respectively. As the main guideline of all of these scoring methods is based on the degree of subluxation, joint congruence and remodeling of the femoral head and acetabulum, these scoring systems may be equal (Table 1). However, these direct comparisons between grades and schemes are considered speculative, due to their subjective nature. ${ }^{34}$ These scoring systems have some particularities: FCI requires a minimum age of 12 months in medium breeds and the OFA method 24 months; FCI scrutinizers are not certified; FCI, OFA, and BVA/KC are voluntary screening schemes. The SVDV is not strongly evaluative of HJL. It is underestimated. The parallel hip-extended positioning and the internal rotation of stifles twist the hip soft tissues, tightening the tensile elements of the joint capsule and may reduce some degree of luxation. ${ }^{26}$

\section{Other imaging techniques}

Ultrasonography in human neonates is the reference technique for the definitive diagnosis of developmental hip dysplasia. ${ }^{35}$ However, the use of ultrasound in puppies for the confirmation of CHD is not recommended, as the acetabulum cannot be evaluated after 8 weeks of age because femoral head ossification and acetabular chondro-osseous alterations are only evident after this age. ${ }^{17}$ Increased synovial fluid volumes in hip joints detected by magnetic resonance imaging in 8-week-old puppies were correlated with later HJL and CHD. ${ }^{17}$ Dynamic ultrasonography was used in

Table I Comparison of CHD scoring systems

\begin{tabular}{llll}
\hline FCI & OFA & BVA/KC Australia & Switzerland \\
\hline A & Excellent & $0-4$ (no $>3 / h i p)$ & $0-2$ \\
& Good & $5-10$ (no $>6 / h i p)$ & \\
& Fair & $11-18$ & \\
B & Borderline & $19-25$ & $3-6$ \\
C & Mild & $26-35$ & $7-12$ \\
D & Moderate & $36-50$ & $13-18$ \\
E & Severe & $51-106$ & $>18$ \\
\hline
\end{tabular}

Notes: FCl's hip dysplasia grading in five categories using as reference the worst hip; OFA hip dysplasia grading in seven categories using as reference the worst hip; BVA/ $\mathrm{KC}$ hip dysplasia score resulting from the sum of both hips, each hip joint is scored between 0 and 53 based on the severity of nine morphological radiographic changes resulting from laxity and degenerative joint disease, with each change scored from 0 (normal) to 6 (worst); Switzerland, the worst joint defines the score of hip dysplasia for the dog, each hip joint is scored between 0 and 30 based on the severity of six morphological radiographic changes resulting from laxity and degenerative joint disease, each change is scored from 0 (normal) to 5 (worst).

Abbreviations: $\mathrm{CHD}$, canine hip dysplasia; $\mathrm{FCl}$, Fédération Cynologique Internationale; OFA, Orthopaedic Foundation for Animals; BVA/KC, British Veterinary Association/Kennel Club. puppies at 8-16 weeks of age, to quantify HJL. ${ }^{36} \mathrm{HJL}$ and osseous acetabular structure can be evaluated confidently using computed tomography. ${ }^{27}$

\section{Prevention and treatment}

Some preventive conservative and surgical treatments have been proposed for young dogs with clinical predisposition for CHD. ${ }^{7,19}$ The main conservative management recommendations are based on limiting food consumption and controlled weight-bearing activity to prevent obesity and develop muscular tissues. ${ }^{1,37}$ Disease-modifying osteoarthritis drugs given by injection are recommended, as they retard breakdown and may promote the synthesis of cartilage matrix and reduce pain and inflammation. ${ }^{20}$ Analgesic or anti-inflammatory medications are effective to manage pain and lameness but should only be used for the short term due to their undesirable side effects. However, the long-term effectiveness of this conservative treatment is questionable, since their ability to prevent the development and progression of osteoarthritis is at best limited. ${ }^{7,19}$

JPS is a surgical treatment used on puppies at 14-20 weeks of age and at risk of developing CHD, ${ }^{19,38}$ with greater improvements achieved when surgery is performed at 15 weeks of age. ${ }^{38}$ JPS is a minimally invasive procedure based on induction of thermal necrosis in chondrocytes of the growth plate of the pubis. ${ }^{19,38}$ The pubic growth plate undergoes premature closure resulting in an underdeveloped ventral pelvis and normal dorsal development. ${ }^{7}$ This modified pelvic growth results in an increase in acetabular coverage of the femoral head and reduction of subluxation forces. ${ }^{38}$ This technique has been recommended in puppies with slight to moderate signs of CHD but not in animals with severe signs of CHD. In the JPS, acetabular ventroversion occurs slowly and in severe cases of CHD the femoral head continues to slide laterally, the dorsal acetabular edge becomes round and femoral head stability is never obtained. ${ }^{19}$

Triple pelvic osteotomy is a reasonable surgical treatment option for CHD being used in animals between 5 and 12 months old, without radiographic signs of DJD and with minimal or clinical signs of CHD. ${ }^{7}$ However, triple pelvic osteotomy is more effective in preventing the development of DJD when used in dogs younger than 7 months of age. ${ }^{7}$ The pelvis is cut in the pubis, ischium, and ilium, rotated and the ilium fixed with a surgical plate. This surgical procedure results in ventrolateral rotation of the acetabulum and provides immediate increased femoral head stability. However, the hips of dogs with extant osteoarthritic changes 
or with a high HJL continue to deteriorate and have a less favorable outcome. ${ }^{7}$ When osteoarthritis is already at an advanced stage, treatment should be performed to alleviate pain and maintain joint function. ${ }^{18,39}$

Femoral head and neck excision reduces the pain produced by abnormal bone to bone hip joint contact, but it does not effectively maintain the full range of hip motion and limb function. The total hip replacement is the best treatment to preserve long-term limb functionality.

\section{Genetic and environmental factors in the pathogenesis of CHD}

$\mathrm{CHD}$ is a complex polygenic disease due to the small additive effect of many genes. ${ }^{4,8}$ Environmental factors such as sex, age, and body weight can influence the expression and severity of the disease. ${ }^{37}$ It appears that CHD is not a congenital disease, hips are normal at birth with adequate femoral head and acetabular congruence. The first 60 days of a puppy's life is thought to be the most critical period in terms of development of the hip joint. ${ }^{16}$ In this period, the depth of the acetabular cavity and the proximal femoral head and neck conformation are susceptible to modeling according to the stress loading. ${ }^{15}$

In a normal congruent hip joint, the normal weight bearing force is transmitted between femoral head and acetabulum across the surface of the articular cartilage. The joint incongruence favors the reduction of contact between the cartilaginous surfaces, the early destruction of chondrocytes by increasing pressure and the cyclic cascade of osteoarthritis. Small synovial joint volume and low intracapsular pressure, high pelvic muscle mass, and a reduced level of the hormones that promote soft tissue relaxation maintain stability and prevent the development of CHD signs. ${ }^{26}$ The HJL is the primary risk factor, well-evaluated in a radiographic study that is associated with CHD development. ${ }^{40}$ Acetabular and proximal femoral head and neck conformation is directly associated with the magnitude of transmitted hip forces. ${ }^{41}$ So, genetic factors associated with $\mathrm{CHD}$ can be related to hip conformation, cartilage susceptibility to pressure forces, joint soft tissues or even to hormonal factors.

Published heritabilities of CHD traits are variable and commonly range between 0.1 to $0.60 .^{12,42}$ Differences of heritability estimates depend on the trait used, calculation method, selection, the population and sample used for estimation..$^{5,42}$ For example, heritability reached as high as 0.83 for passive hip laxity in the Estrela Mountain dog breed from Portugal. ${ }^{3}$ The genetic improvement used in selection of traits with higher heritabilities and similar selection pressures will be bigger per generation. ${ }^{1}$

\section{Selection of breeding stock with low hip scores - progress toward reducing incidences of hip dysplasia}

Because there is no ideal medical or surgical treatment, veterinarians in practice are at the forefront, and their main focus is on prevention of CHD through reproductive control. ${ }^{43}$ Selection of breeding stock has clearly been a priority intervention area of veterinary medicine. Control CHD programs based on radiographic phenotype quality of hips were used in some countries as early as the $1960 \mathrm{~s} .{ }^{44} 46$ These programs were based on radiographic screening of CHD using the SVDV and scores of hip quality based on DJD signs and hip congruence. Selection of breeding stock was based on an individual dog's hip phenotype and subjective pedigree evaluation performed by the breeder. The results of phenotype-based genetic screening on CHD prevalence and severity are somewhat disparate in different countries and breeds. When the CHD control schemes are voluntary, as the OFA, FCI, and BVA/KC, only the better hip phenotypes are scrutinized and the studies performed using these databases are biased. ${ }^{2,42}$ Using the OFA scoring scheme and the best linear unbiased prediction method for the estimation of breeding values and its application in the selection for hip joint conformation, for Labrador Retrievers the total genetic improvement in four decades (1970-2007) corresponded to only $\sim 17 \%$ of the total phenotypic standard deviation. ${ }^{12}$ However, radiographs of dogs with normal-appearing hips are several times more likely to be submitted for evaluation in the OFA system than radiographs of dogs that are severely dysplastic. ${ }^{47}$ For example, in a closed breeding colony of German Shepherd dogs and Labrador Retrievers, CHD prevalence over five generations of selection decreased from $55 \%$ to $24 \%$, and from $30 \%$ to $10 \%$, respectively. ${ }^{46}$ Selective breeding against CHD was less effective in decreasing its prevalence and severity in Sweden. ${ }^{44}$ In other countries, such as Finland, the general CHD control program was even considered ineffective in reducing the prevalence of CHD in various dog breeds. ${ }^{45}$ For the PennHIP method, there are no reports of its effectiveness in reducing the prevalence of CHD in different dog populations. Theoretically, it is a promising method since studies have shown that HJL has a higher heritability than the CHD scores based on DJD. The lack of desired success of CHD control programs that rely totally on individual phenotype has been due partly to its sensitivity to environmental factors. Animals with a normal 
individual radiographic phenotype can still be carriers of CHD genes, which will be transmitted to their offspring and maintained in the population. ${ }^{48}$ Estimated breeding values (EBV) are commonly used in farm animal selection for complex polygenic traits (phenotype expression is influenced by environmental factors), such as milk yield or growth rate. ${ }^{28,49}$ So, the phenotypic expressions of these traits are very similar to CHD, determined by heredity and environment. The EBV for CHD is a genetic parameter derived from the hip quality of relatives, and is thus more representative of the dog's genetic quality, ${ }^{12,44}$ and allows monitoring of the genetic trends in dog populations, ${ }^{50}$ being recommended for $\mathrm{CHD}$ selection purposes. ${ }^{51,52}$

With the rapid development of high-throughput sequencing technology and emergence of high-density genome-wide single nucleotide polymorphisms (SNPs) canine arrays, associations between genetic markers in linkage disequilibrium and CHD genes have been discovered. ${ }^{14,42}$ The molecular genetic information can be applied for CHD selection purposes, particularly if the most informative SNPs are used to estimate the genomic breeding value (GBV) of an individual. Such genomic selection was successfully applied in livestock animal breeding programs and can be used for selection against prevalence of undesired traits with greater genetic improvement. ${ }^{10,42,43,53}$ In the near future, GBV might become the recommended method to improve hip quality in CHD control schemes. ${ }^{12,43,53}$ In a particular dog breed, pedigree and phenotypic data can be used to obtain EBV and combined with genomic data to derive a predictive formula for the GBV. ${ }^{12}$ Then, the genotyping of a puppy for a set of informative SNPs can be combined with radiographic information, and used to determine the susceptibility to CHD and make decisions regarding breed management.

\section{Genome-wide association studies (GWAS) and genetic analyses in the identification of susceptibility alleles}

The genetic etiology of CHD has been proven and accepted by the scientific community. ${ }^{54}$ The first molecular studies for CHD diagnosis were developed by Todhunter et al in the 1990s at Cornell University, who began by searching for molecular genetic markers that were linked to quantitative trait loci (QTL) responsible for different CHD phenotypes. , $^{9,55}$ To optimize the linkage of genes to CHD traits an outcross between breeds with high and low susceptibility to develop CHD, Labrador Retrievers and Greyhounds, respectively, was implemented. Twelve chromosomes were identified to harbor putative QTL for different CHD traits. ${ }^{9}$ QTL were also associated to the Norberg angle ${ }^{8}$ and acetabular osteophyte formation. ${ }^{56}$ Recently, more QTL were associated with other CHD traits. ${ }^{10,57}$

Pedigree and CHD phenotype analysis showed some evidence of a major QTL (contributing about $20 \%$ of variance) associated to CHD in several studies. ${ }^{46,58-60}$

However, the QTL region may contain hundreds of genes and the identification of genes remains problematic. ${ }^{4}$ The strategy that is followed by some researchers is to refine the QTL interval using SNPs and across-breedmapping thus reducing the linkage disequilibrium interval. ${ }^{4}$ Unrelated affected animals with CHD probably share more common disease alleles than an unaffected dog population. ${ }^{4}$ The associated SNPs might be physically next to the responsible gene. ${ }^{14}$ GWAS consider the joint effect of multiple SNPs, being much more effective than individual SNP analysis, in the identification of common genetic variants for complex diseases. ${ }^{14}$ In eight different dog breeds using GWAS, four SNPs were significantly associated with CHD on CFA3, 11, and 30, and two with osteoarthritis on CFA17 and 37. ${ }^{14}$ In German Shepherd dogs, 13 SNPs were also associated with CHD on chromosome CFA14 and 37, ${ }^{1}$ CFA19, 24, 26, and 34, ${ }^{11}$ and CFA3, 9, 26, 33, and 34. ${ }^{62}$ In other recent studies on Labrador Retrievers, four SNPs were associated with CHD on chromosome CFA1 and 21, ${ }^{10}$ and 31 SNPs on CFA1, 5, 8, 15, 20, 25, and 32 positioned within or in the vicinity of 24 different genes (Table 2). ${ }^{63}$ Candidate genes involved in hypertrophic differentiation of chondrocytes and extracellular matrix integrity of basement membrane and cartilage were located in significantly associated regions on CFA1, 8, 20, and $25 .{ }^{63}$ These results confirm the complex genetic architecture of $\mathrm{CHD}$, based on many genes with small individual effect, which encourages circumspection about a marker-assisted, accurate CHD diagnostic test in the near future. The immediate importance of CHD molecular diagnosis will probably be their use in genomic (many markers assessed for their combined contribution) selection.

One mutation in the FBN2 gene on CFA11 chromosome was significantly associated with CHD in Labrador Retrievers and other dog breeds. ${ }^{64}$ However, other genes must be involved in CHD because the FBN2 locus only explains a small part of the genetic trait variation in CHD. ${ }^{64}$ Studies on QTL and/or SNPs associated with other phenotypes of $\mathrm{CHD}$, such as the passive hip laxity, could provide additional information on the genetic basis of this condition. Passive hip laxity is the highest risk factor for CHD and is the trait associated with the highest heritability. ${ }^{3,40}$ 
Table 2 Summary of the SNPs and nearby candidate genes identified in six genome-wide association studies of canine hip dysplasia and other related traits in reference breeds

\begin{tabular}{|c|c|c|c|c|c|c|}
\hline SNP/trait & CFA & $\begin{array}{l}\text { Position } \\
\text { (bp) }\end{array}$ & $\begin{array}{l}\text { Allele } \\
\text { (nt) }\end{array}$ & $\begin{array}{l}\text { Distance } \\
(\mathrm{Mb}) / \text { position } \\
\text { in gene }\end{array}$ & Gene(s) & Reference/breed \\
\hline BICF2S2459425/CHD & 3 & 74720873 & G & 0.900 & $E V C, E V C 2$ & Zhou et al'4/eight different \\
\hline BICF2P550340/CHD & 11 & 32935770 & $\mathrm{~T}$ & 0.220 & PTPRD & breeds \\
\hline BICF2S23432I43/CHD & 11 & 57517597 & G & 0.394 & COLI5AI & \\
\hline BICF2P79926I/CHD & 30 & 13883057 & C & 0.109 & MAGPI & \\
\hline BICF2G63020552/OA & 17 & 48092910 & $\mathrm{~T}$ & 0.060 & REG3A & \\
\hline BICF2PI242205/OA & 37 & 17299306 & C & 0.070 & PARD3B & \\
\hline BICF2PI089246/CHD & 14 & 23811133 & C & 0.183 & PON2 & Pfahler and Distl|61/BMD \\
\hline BICF2PI282232/CHD & 14 & 59537633 & $\mathrm{~T}$ & NA & NA & \\
\hline BICF2S23052396/CHD & 37 & $250955 I I$ & $A$ & $0.36 \mathrm{I}$ & FNI & \\
\hline $\mathrm{G}: 37139132 \mathrm{G}>\mathrm{A} / \mathrm{CHD}$ & 3 & 77186 & A & NA & PGM2 & Fels et $\mathrm{a}^{62} /$ German Shepherd \\
\hline BICF2S22937555/CHD & 9 & 54312 & G & NA & NA & dog \\
\hline BICF2P844355/CHD & 26 & 32016 & A & NA & NA & \\
\hline $\mathrm{G}: 973418 \mathrm{~T}>\mathrm{G} / \mathrm{CHD}$ & 33 & 3975 & $\mathrm{~T}$ & NA & EPHA3, EPHA6, PCNP & \\
\hline $\mathrm{G}: 4052195 \mathrm{~T}>\mathrm{C} / \mathrm{CHD}$ & 33 & 7022 & $\mathrm{~T}$ & NA & & \\
\hline G:7967386T >C/CHD & 33 & 10983 & C & NA & & \\
\hline G:4I487IG[A/CHD & 34 & 3422 & A & NA & $\begin{array}{l}\text { TRIO, SEMA5A, SLC6A3, } \\
\text { FGFI2 }\end{array}$ & \\
\hline G:48462I5A $>$ G/CHD & 34 & 7851 & G & NA & & \\
\hline G:I I 239992A > G/CHD & 34 & 14246 & A & NA & & \\
\hline G:I I5474| ITT>G/CHD & 34 & 27034 & G & NA & & \\
\hline TIGRP2P265674/CHD & 19 & 35.533 & C & NA & NA & Fels and Distl"'/German \\
\hline BICF2S2367279/CHD & 24 & 28.944 & G & NA & $S R C$ & Shepherd dog \\
\hline BICF2P28I364/CHD & 26 & 17.181 & G & NA & KSR2 & \\
\hline BICF2PI086886/CHD & 34 & 4.239 & $\mathrm{~T}$ & 0.7 & TRIO & \\
\hline BICF2P355865/CHD & 34 & 39.346 & A & NA & NA & \\
\hline BICF2P2I9706/left CrAE & 1 & 100106009 & G & $\begin{array}{l}\text { Genes in region } \\
99-110 \mathrm{Mb}\end{array}$ & $\begin{array}{l}\text { SHC3, SEMA4D, OMD, OGN, } \\
\text { PHF2, BARXI, ZNF677 }\end{array}$ & $\begin{array}{l}\text { Sánchez-Molano et al }{ }^{10} / \text { Labrador } \\
\text { Retriever }\end{array}$ \\
\hline BICF2S2443I86/left CrAE & I & $100|3826|$ & $A$ & & & \\
\hline BICF2PI 285984/left CrAE & I & $1077 \mid 9908$ & G & & & \\
\hline BICF2P429643/right & 21 & 43337454 & G & 1.5 & OTOG, SOX6, SAA, MYODI, & \\
\hline Norberg angle & & & & & SERGEF & \\
\hline $\mathrm{NA} / \mathrm{CHD}$ & 1 & 70938018 & T/A & Intron & LAMA2 & Lavrijsen et al ${ }^{63} /$ Labrador Retriever \\
\hline $\mathrm{NA} / \mathrm{CHD}$ & 1 & 70997779 & $\mathrm{~A} / \mathrm{T}$ & $\begin{array}{l}\text { Exon, } \\
\text { synonymous }\end{array}$ & LAMA2 & \\
\hline $\mathrm{NA} / \mathrm{CHD}$ & 5 & 59194609 & $\mathrm{G} /-$ & $3^{\prime}$-UTR & KLHLI 7 & \\
\hline $\mathrm{NA} / \mathrm{CHD}$ & 5 & 62929475 & $\mathrm{C} / \mathrm{T}$ & $5^{\prime}-$ UTR & NPHP4 & \\
\hline $\mathrm{NA} / \mathrm{CHD}$ & 8 & 29247021 & $\mathrm{C} / \mathrm{T}$ & $3^{\prime}$-UTR & $L R R I$ & \\
\hline $\mathrm{NA} / \mathrm{CHD}$ & 8 & 31496895 & $\mathrm{C} / \mathrm{T}$ & Downstream & PTGDR & \\
\hline $\mathrm{NA} / \mathrm{CHD}$ & 8 & 31496910 & $\mathrm{C} / \mathrm{T}$ & & & \\
\hline $\mathrm{NA} / \mathrm{CHD}$ & 20 & 45260332 & $A / G$ & $\begin{array}{l}\text { Exon, } \\
\text { non-synonymous }\end{array}$ & LTF & \\
\hline $\mathrm{NA} / \mathrm{CHD}$ & 20 & 46671813 & $\mathrm{C} / \mathrm{G}$ & Intron & PBX4 & \\
\hline $\mathrm{NA} / \mathrm{CHD}$ & 20 & 46706734 & $\mathrm{~A} / \mathrm{G}$ & $3^{\prime}$-UTR & CILP2 & \\
\hline $\mathrm{NA} / \mathrm{CHD}$ & 20 & 47636184 & $\mathrm{G} / \mathrm{A}$ & $3^{\prime}$-UTR & GDFI5 & \\
\hline $\mathrm{NA} / \mathrm{CHD}$ & 20 & $477 \mid 4388$ & $\mathrm{G} / \mathrm{A}$ & $5^{\prime}$-UTR & LSM4 & \\
\hline $\mathrm{NA} / \mathrm{CHD}$ & 20 & 4807 II 92 & $\mathrm{G} / \mathrm{A}$ & Upstream & INSL3 & \\
\hline $\mathrm{NA} / \mathrm{CHD}$ & 20 & 48243399 & $\mathrm{G} /-$ & 3'-UTR & NA & \\
\hline $\mathrm{NA} / \mathrm{CHD}$ & 20 & $48804 \mid 30$ & $\mathrm{G} / \mathrm{A}$ & $\begin{array}{l}\text { Exon, } \\
\text { synonymous }\end{array}$ & NWDI & \\
\hline $\mathrm{NA} / \mathrm{CHD}$ & 20 & 49019261 & $\mathrm{~T} / \mathrm{C}$ & Intron & CHERP & \\
\hline $\mathrm{NA} / \mathrm{CHD}$ & 20 & 49318725 & $\mathrm{C} / \mathrm{T}$ & $\begin{array}{l}\text { Exon, } \\
\text { synonymous }\end{array}$ & CIB3 & \\
\hline $\mathrm{NA} / \mathrm{CHD}$ & 25 & 47629272 & $\mathrm{C} / \mathrm{T}$ & Upstream & INPP5D & \\
\hline
\end{tabular}


Table 2 (Continued)

\begin{tabular}{|c|c|c|c|c|c|c|}
\hline SNP/trait & CFA & $\begin{array}{l}\text { Position } \\
\text { (bp) }\end{array}$ & $\begin{array}{l}\text { Allele } \\
\text { (nt) }\end{array}$ & $\begin{array}{l}\text { Distance } \\
(\mathrm{Mb}) / \text { position } \\
\text { in gene }\end{array}$ & Gene(s) & Reference/breed \\
\hline $\mathrm{NA} / \mathrm{CHD}$ & 25 & 47666842 & $\mathrm{G} / \mathrm{A}$ & $\begin{array}{l}\text { Exon, } \\
\text { synonymous }\end{array}$ & INPP5D & \\
\hline $\mathrm{NA} / \mathrm{CHD}$ & 25 & 47685188 & $\mathrm{C} / \mathrm{T}$ & Intron & INPP5D & \\
\hline $\mathrm{NA} / \mathrm{CHD}$ & 25 & 48075297 & $\mathrm{C} / \mathrm{G}$ & $\begin{array}{l}\text { Exon, } \\
\text { non-synonymous }\end{array}$ & LOCI00688622 & \\
\hline $\mathrm{NA} / \mathrm{CHD}$ & 25 & 48076278 & $\mathrm{G} / \mathrm{A}$ & Downstream & LOCI00688622 & \\
\hline $\mathrm{NA} / \mathrm{CHD}$ & 25 & 48396330 & $\mathrm{C} / \mathrm{T}$ & Intron & SPP2 & \\
\hline $\mathrm{NA} / \mathrm{CHD}$ & 25 & 50050076 & $\mathrm{G} / \mathrm{A}$ & Downstream & $A S B / 8$ & \\
\hline $\mathrm{NA} / \mathrm{CHD}$ & 25 & 50228063 & $\mathrm{C} / \mathrm{G}$ & Intron & IQCAI & \\
\hline $\mathrm{NA} / \mathrm{CHD}$ & 25 & 51029326 & $\mathrm{G} / \mathrm{A}$ & Intron & COL6A3 & \\
\hline $\mathrm{NA} / \mathrm{CHD}$ & 25 & 51031100 & $\mathrm{~A} / \mathrm{G}$ & $\begin{array}{l}\text { Exon, } \\
\text { synonymous }\end{array}$ & COL6A3 & \\
\hline $\mathrm{NA} / \mathrm{CHD}$ & 25 & 51040259 & $\mathrm{~A} / \mathrm{G}$ & & & \\
\hline $\mathrm{NA} / \mathrm{CHD}$ & 25 & 51046607 & $\mathrm{G} / \mathrm{A}$ & & & \\
\hline $\mathrm{NA} / \mathrm{CHD}$ & 25 & 51736576 & $\mathrm{~T} / \mathrm{C}$ & Upstream & HES6 & \\
\hline $\mathrm{NA} / \mathrm{CHD}$ & 32 & 11265116 & $-/ T$ & Downstream & LOC487839 & \\
\hline
\end{tabular}

Notes: Single nucleotide polymorphisms (SNPs) are categorized by traits; gene symbols follow international nomenclature guidelines; distance is shown in Mb. Abbreviations: CHD, canine hip dysplasia; OA, osteoarthritis; CrAE, cranial acetabular edge; CFA, Canis familiaris autosome; bp, position in base pair; nt, nucleotide allele; Mb, megabase; BMD, Bernese Mountain dog; NA, not applicable; UTR, untranslated region.

Genetic studies regarding the developmental hip dysplasia in humans were unable to make much progress, so knowledge on the loci-linked hip dysplasia in humans is still limited. ${ }^{12}$ Despite recent developments in whole-genome analysis in humans, with the finding of a number of genetic variants associated with this condition in affected patients, ${ }^{65,66}$ understanding the genetics of hip dysplasia in humans can benefit from similar studies in the dog.

\section{Prospects for the development of commercially available DNA tests for screening and diagnosis}

A DNA-based test for CHD is a desirable tool for early identification of dogs susceptible or resistant to the disease. In 2012, such a test was registered by Bioiberia. Called Dysgen, it was the first commercial marker-based DNA test for susceptibility to CHD in the Labrador Retriever breed. This test analyzes blood samples using a DNA kit containing seven SNPs. ${ }^{13}$ The Dysgen diagnosis is reported as a prediction, classifying the dog into a risk group for developing CHD - minimal, low, moderate, and high. However, the performance of the Dysgen diagnosis test was not independently tested and there are no published studies reporting its success in the control for CHD at the population level. Breeding of dogs with minimal or low risk of developing CHD is recommended by the manufacturer. This is a first step in the molecular diagnosis of CHD, but until all the genes involved in the disease are detected, CHD control programs continue to require the combination of an accurate phenotype screening, EBV, and the information of available genetic tests. Particularly, if the heritability of the trait is low effectiveness of selection will benefit from combining information on major gene genotypes and EBV. Moreover, if we consider that CHD affects a rather large group of distinct dog breeds, from the Alaskan Malamute to the Portuguese Water Dog and which are raised in different environments, we require a deep understanding of the genetics underlying the incidence of this condition at the population level.

\section{Conclusion}

Despite phenotypic screening and breeding programs, CHD continues to be one of the most common orthopedic hereditary diseases in dogs. There is no ideal diagnosis or treatment for CHD and reproductive control schemes have been, in the last 50 years, a priority area of veterinary medicine to deal with the disease.

The genetic architecture of CHD is complex, as the many associated genes have small individual effect. This fact makes the development of a marker-assisted accurate CHD diagnosis test difficult, despite intensive research worldwide.

The molecular diagnosis of CHD will be based on genomic selection until all contributing and critical mutations are identified, and may have a significant impact for a better understanding of the genetic basis of similar conditions in humans. 


\section{Acknowledgments}

$C$ Ginja received funding from the European Union Seventh Framework Programme (FP7/2007-2013) under grant agreement number PCOFUND-GA-2009-246542 and from the Fundação para a Ciência e a Tecnologia, Portugal, through a Marie Curie/Welcome II fellowship (Ref DFRH/ WIIA/15/2011). The authors are grateful to R Todhunter (College of Veterinary Medicine, Cornell University) for expert critical review of the manuscript and helpful comments.

\section{Disclosure}

The authors declare no conflicts of interest regarding this work.

\section{References}

1. Ginja MM, Silvestre AM, Gonzalo-Orden JM, Ferreira AJ. Diagnosis, genetic control and preventive management of canine hip dysplasia: a review. Vet J. 2010;184(3):269-276.

2. Ginja MM, Silvestre AM, Colaço J, et al. Hip Dysplasia in Estrela mountain dogs - prevalence and genetic trends 1991-2005. Vet J. 2009; 182(2):275-282

3. Ginja MM, Silvestre AM, Ferreira AJ, et al. Passive hip laxity in Estrela mountain dog - distraction index, heritability and breeding values. Acta Vet Hung. 2008;56(3):303-312.

4. Zhu L, Zhang Z, Friedenberg S, et al. The long (and winding) road to gene discovery for canine hip dysplasia. Vet J. 2009;181(2):97-110.

5. Silvestre AM, Ginja MM, Ferreira AJ, Colaço J. Comparison of estimates of hip dysplasia genetic parameters in Estrela Mountain Dog using linear and threshold models. J Anim Sci. 2007;85(8):1880-1884.

6. Barr AR, Denny HR, Gibbs C. Clinical hip dysplasia in growing dogs: the long-term results of conservative management. J Small Anim Pract. 1987;28(4):243-252.

7. Manley PA, Adams WM, Danielson KC, Dueland RT, Linn KA. Long-term outcome of juvenile pubic symphysiodesis and triple pelvic osteotomy in dogs with hip dysplasia. J Am Vet Med Assoc. 2007;230(2): 206-210.

8. Chase K, Lawler DF, Adler FR, Ostrander EA, Lark KG. Bilaterally asymmetric effects of quantitative trait loci (QTLs): QTLs that affect laxity in the right versus left coxofemoral (hip) joints of the dog (Canis familiaris). Am J Med Genet A. 2004;124A(3):239-247.

9. Todhunter RJ, Mateescu R, Lust G, et al. Quantitative trait loci for hip dysplasia in a cross-breed canine pedigree. Mamm Genome. 2005;16(9): 720-730.

10. Sánchez-Molano E, Woolliams JA, Pong-Wong R, et al. Quantitative trait loci mapping for canine hip dysplasia and its related traits in UK Labrador Retrievers. BMC Genomics. 2014;15:833.

11. Fels L, Distl O. Identification and validation of quantitative trait loci (QTL) for canine hip dysplasia (CHD) in German Shepherd Dogs. PLoS One. 2014;9(5):e96618.

12. Breur GJ, Lambrechts NE, Todhunter RJ. 2012. The Genetics of Canine Orthopaedic Traits. In: Ostrander EA, Ruvinsky A, editors. The Genetics of the dog. New York, CABI; 2012:136-160.

13. Plant and Animal Genome XXI [homepage on the Internet]. Sanchez A, Segarra S, Blume V, et al. DNA Test to Evaluate Genetic Predisposition of Labrador Retrievers to Developing Canine Hip Dysplasia: Applications. P0630. Proceedings of the XXI Plant and Animal Genome Conference; 2013. Available from: https://pag.confex.com/pag/xxi/ webprogram/Paper6682.html. Accessed December 4, 2014.

14. Zhou Z, Sheng X, Zhang Z, et al. Differential genetic regulation of canine hip dysplasia and osteoarthritis. PLoS One. 2010;5(10):e13219.
15. Wenger DR, Bomar JD. Human hip dysplasia: evolution of current treatment concepts. J Orthop Sci. 2003;8(2):264-271.

16. Riser WH. The dog as a model for the study of hip dysplasia: growth, form, and development of normal and dysplastic hip joint. Vet Pathol. 1975;12(4):244-334.

17. Ginja MM, Ferreira AJ, Jesus SS, et al. Comparison of clinical, radiographic, computed tomographic and magnetic resonance imaging methods for early prediction of canine hip dysplasia. Vet Radiol Ultrasound. 2009;50(2):135-143.

18. Farrell M, Clements DN, Mellor D, et al. Retrospective evaluation of the long-term outcome of non-surgical management of 74 dogs with clinical hip dysplasia. Vet Rec. 2007;160(15):506-511.

19. Vezzoni A, Dravelli G, Vezzoni L, et al. Comparison of conservative management and juvenile pubic symphysiodesis in the early treatment of canine hip dysplasia. Vet Comp Orthop Traumatol. 2008(3);21: 267-279.

20. Lust G, Williams AJ, Burton-Wurster N, Beck KA, Rubin G. Effects of intramuscular administration of glycosaminoglycan polysulfates on signs of incipient hip dysplasia in growing pups. Am J Vet Res. 1992; 53(10):1836-1843.

21. Fry TR, Clark DM. Canine hip dysplasia: clinical signs and physical diagnosis. Vet Clin North Am Small Anim Pract. 1992(3);22: 551-558.

22. Vezzoni A, Dravelli G, Corbari A, et al. The early diagnosis of canine hip dysplasia. EJCAP. 2005;15(2):173-184.

23. Chalman JA, Butler HC. Coxofemoral joint laxity and the Ortolani sign. J Am Anim Hosp Assoc. 1985(6);21:671-676.

24. Ginja MM, Gonzalo-Orden JM, Melo-Pinto P, et al. Early hip laxity examination in predicting moderate and severe hip dysplasia in Estrela mountain dog. J Small Anim Pract. 2008;49(12):641-646.

25. Puerto DA, Smith GK, Gregor TP, et al. Relationship between results of the Ortolani method of hip joint palpation and distraction index, Norberg angle, and hip score in dogs. J Am Vet Med Assoc. 1999;214(4): 497-501.

26. Smith GK, Biery DN, Gregor TP. New concepts of coxofemoral joint stability and the development of a clinical stress-radiographic method for quantitating hip joint laxity in the dog. J Am Vet Med Assoc. 1990; 196(1):59-70.

27. Farese JP, Todhunter RJ, Lust G, Williams AJ, Dykes NL. Dorsolateral subluxation of hip joints in dogs measured in a weight-bearing position with radiography and computed tomography. Vet Surg. 1998;27(5): 393-405.

28. Flückiger MA, Friedrich GA, Binder H. A radiographic stress technique for evaluation of coxofemoral joint laxity in dogs. Vet Surg. 1999; 28(1):1-9.

29. Corley EA. Role of the Orthopedic Foundation for Animals in the control of canine hip dysplasia. Vet Clin North Am Small Anim Pract. 1992;22(3):579-593.

30. Gibbs C. The BVA/KC scoring scheme for control of hip dysplasia, interpretation of criteria. Vet Rec. 1997;141(11):275-284.

31. Farese JP, Lust G, Williams AJ, Dykes NL, Todhunter RJ. Comparison of measurements of dorsolateral subluxation of the femoral head and maximal passive laxity for evaluation of the coxofemoral joint in dogs. Am J Vet Res. 1999;60(12):1571-1576.

32. Whittington K, Banks WC, Carlson WD, et al. Report of panel on canine hip dysplasia. J Am Vet Med Assoc. 1961;139:791-806.

33. Flückiger $M$. The standardised analysis of radiographs for hip dysplasia in dogs. Objectifying a subjective process. EJCAP. 1994;2:39-44.

34. Soo M, Worth A. Canine hip dysplasia: phenotypic scoring and the role of estimated breeding value analysis. N Z Vet J. 2015;63(2):69-78.

35. Gerscovich EO. A radiologist's guide to the imaging in the diagnosis and treatment of developmental dysplasia of the hip. I. General considerations, physical examination as applied to real-time sonography and radiography. Skeletal Radiol. 1997;26(7):386-397.

36. O'Brien RT, Dueland RT, Adams WC, Meinen J. Dynamic ultrasonographic measurement of passive coxofemoral joint laxity in puppies. J Am Anim Hosp Assoc. 1997;33(3):275-281. 
37. Kealy RD, Lawler DF, Ballam JM, et al. Evaluation of the effect of limited food consumption on radiographic evidence of osteoarthritis in dogs. J Am Vet Med Assoc. 2000;217(11):1678-1680.

38. Patricelli AJ, Dueland RT, Adams WM, et al. Juvenile pubic symphysiodesis in dysplastic puppies at 15 and 20 weeks of age. Vet Surg. 2002; 31(5):435-444.

39. Johnson AL, Smith SW, Pijanowski GJ, Hungerford LL. Triple pelvic osteotomy: effect on limb function and progression of degenerative joint disease. J Am Anim Hosp Assoc. 1998;34(3):260-264.

40. Smith GK, Popovitch CA, Gregor TP, Shofer FS. Evaluation of risk factors for degenerative joint disease associated with hip dysplasia in dogs. J Am Vet Med Assoc. 1995;206(5):642-647.

41. Weigel JP, Wasserman JF. Biomechanics of the normal and abnormal hip joint. Vet Clin North Am Small Anim Pract. 1992;22(3):513-528.

42. Hou Y, Wang Y, Lu X, et al. Monitoring Hip and Elbow Dysplasia achieved modest genetic improvement of 74 dog breeds over 40 years in USA. PLoS One. 2013;8(10):e76390.

43. Sánchez-Molano E, Woolliams JA, Blott SC, Wiener P. Assessing the impact of genomic selection against hip dysplasia in the Labrador Retriever dog. J Anim Breed Genet. 2014;131(2):134-145.

44. Swenson L, Audell L, Hedhammar A. Prevalence and inheritance of and selection for hip dysplasia in seven breeds of dogs in Sweden and benefit: cost analysis of a screening and control program. J Am Vet Med Assoc. 1997;210(2):207-214.

45. Leppänen M, Mäki K, Juga J, Saloniemi H. Factors affecting hip dysplasia in German shepherd dogs in Finland: efficacy of the current improvement programme. J Small Anim Pract. 2000;41(1):19-23.

46. Leighton EA. Genetics of canine hip dysplasia. J Am Vet Med Assoc. 1997;210(10):1474-1479.

47. Paster ER, LaFond E, Biery DN, et al. Estimates of prevalence of hip dysplasia in Golden Retrievers and Rottweilers and the influence of bias on published prevalence figures. J Am Vet Med Assoc. 2005;226(3): 387-392.

48. Mäki K, Liinamo AE, Ojala M. Estimates of genetic parameters for hip and elbow dysplasia in Finnish Rottweilers. J Anim Sci. 2000;78(5): 1141-1148.

49. Hou Y, Wang Y, Lust G, et al. Retrospective analysis for genetic improvement of hip joints of cohort Labrador Retrievers in the United States: 1970-2007. PLoS One. 2010;5(2):e9410.

50. Wilson B, Nicholas FW, Thomson PC. Selection against canine hip dysplasia: success or failure? Vet J. 2011;189(2):160-168.

51. Wilson BJ, Nicholas FW, James JW, et al. Genetic correlations among canine hip dysplasia radiographic traits in a cohort of Australian German Shepherd Dogs, and implications for the design of a more effective genetic control program. PLoS One. 2013;8(11):e78929.

52. Malm S, Sørensen AC, Fikse WF, Strandberg E. Efficient selection against categorically scored hip dysplasia in dogs is possible using best linear unbiased prediction and optimum contribution selection: a simulation study. J Anim Breed Genet. 2013;130(2):154-164.
53. Guo G, Zhou Z, Wang Y, et al. Canine hip dysplasia is predictable by genotyping. Osteoarthritis Cartilage. 2011;19(4):420-429.

54. Leighton EA, Linn JM, Willham RL, Castleberry MW. A genetic study of canine hip dysplasia. Am J Vet Res. 1977;38(2):241-244.

55. Todhunter RJ, Acland GM, Olivier M, et al. An outcrossed canine pedigree for linkage analysis of hip dysplasia. J Hered. 1999;90(1); 83-92.

56. Chase K, Lawler DF, Carrier DR, Lark KG. Genetic regulation of osteoarthritis: A QTL regulating cranial and caudal acetabular osteophyte formation in the hip joint of the $\operatorname{dog}$ (Canis familiaris). Am JMed Genet A. 2005;135(3):334-335.

57. Marschall Y, Distl O. Mapping quantitative trait loci for canine hip dysplasia in German Shepherd dogs. Mamm Genome. 2007;18(12): 861-870.

58. Todhunter RJ, Bliss SP, Casella G, et al. Genetic structure of susceptibility traits for hip dysplasia and microsatellite informativeness of an outcrossed canine pedigree. J Hered. 2003;94(1):39-48.

59. Janutta V, Hamann H, Distl O. Complex segregation analysis of canine hip dysplasia in German shepherd dogs. J Hered. 2006;97(1):13-20.

60. Mäki K, Janss LL, Groen AF, Liinamo AE, Ojala M. An indication of major genes affecting hip and elbow dysplasia in four Finnish dog populations. Heredity (Edinb). 2004;92(5):402-408.

61. Pfahler S, Distl O. Identification of quantitative trait loci (QTL) for canine hip dysplasia and canine elbow dysplasia in Bernese mountain dogs. PLoS One. 2012;7(11):e49782.

62. Fels L, Marschall Y, Philipp U, Distl O. Multiple loci associated with canine hip dysplasia (CHD) in German shepherd dogs. Mamm Genome. 2014; 25(5-6):262-269.

63. Lavrijsen IC, Leegwater PA, Martin AJ, et al. Genome wide analysis indicates genes for basement membrane and cartilage matrix proteins as candidates for hip dysplasia in Labrador Retrievers. PLoS One. 2014; 30;9(1):e87735.

64. Friedenberg SG, Zhu L, Zhang Z, et al. Evaluation of a fibrillin 2 gene haplotype associated with hip dysplasia and incipient osteoarthritis in dogs. Am J Vet Res. 2011;72(4):530-540.

65. Feldman G, Dalsey C, Fertala K, et al. The Otto Aufranc Award: Identification of a $4 \mathrm{Mb}$ region on chromosome 17q21 linked to developmental dysplasia of the hip in one 18-member, multigeneration family. Clin Orthop Relat Res. 2010;468(2):337-344.

66. Feldman GJ, Parvizi J, Sawan H, Erickson JA, Peters CL. Linkage mapping and whole exome sequencing identify a shared variant in CX3CR1 in a large multi-generation family. J Arthroplasty. 2014; 29(9 Suppl):238-241.
Veterinary Medicine: Research and Reports

\section{Publish your work in this journal}

Veterinary Medicine: Research and Reports is an international, peer-reviewed, open access journal publishing original research, case reports, editorials, reviews and commentaries on all areas of veterinary medicine. The manuscript management system is completely online and includes a very quick and fair peer-review system.

\section{Dovepress}

Visit http://www.dovepress.com/testimonials.php to read real quotes from published authors. 